\title{
Expression of Mucins in Mucoid Otitis Media
}

\author{
Jizhen Lin, ${ }^{1}$ Yasuhiro Tsuboi, ${ }^{1}$ Frank Rimeld, ${ }^{1}$ George Liu, ${ }^{2}$ Katsuhiro Toyama, \\ Hirokazu Kawano, ${ }^{1}$ Michael M. Paparella, ${ }^{2}$ and Samuel B. Ho ${ }^{3,4}$ \\ ${ }^{1}$ Department of Otolaryngology, Otitis Media Research Center, University of Minnesota School of Medicine, Minneapolis, MN \\ 55455, USA \\ ${ }^{2}$ Minnesota Ear, Head and Neck Clinic, Minneapolis, MN 55455, USA \\ ${ }^{3}$ Department of Internal Medicine, University of Minnesota School of Medicine, Minneapolis, MN 55455, USA \\ ${ }^{4}$ Veterans Administration Medical Center, Minneapolis, MN 55455, USA
}

Received: 22 May 2002; Accepted: 7 February 2003; Online publication: 22 April 2003

\section{ABSTRACT}

A hallmark of mucoid otitis media (MOM, i.e., chronic otitis media with mucoid effusion) is mucus accumulation in the middle ear cavity, a condition that impairs transduction of sounds in the ear and causes hearing loss. The mucin identities of mucus and the underlying mechanism for the production of mucins in MOM are poorly understood. In this study, we demonstrated that the MUC5B and MUC4 were major mucins in MOM that formed distinct treelike polymers (mucus strands). The MUC5B and MUC4 mRNAs in the middle ear mucosa with MOM were up regulated 5-fold and 6-fold, compared with the controls. This upregulation was accompanied by the extensive proliferation of the MUC5B- and MUC4producing cells in the middle ear epithelium. Further study indicated that the mucin hyperproduction was significantly linked to $\mathrm{CD} 4^{+}$and $\mathrm{CD} 8^{+} \mathrm{T}$ cells and/or $\mathrm{CD}^{+} 8^{+}$monocyte macrophages. It suggests that MUC5B and MUC4 expression may be regulated by the products of these cells.

Keywords: Mucins, mucoid otitis media, mucous cell metaplasia, humans
Correspondence to: Jizhen Lin • 2001 Sixth St. S.E. • Rm. 216, LRB • Minneapolis, MN 55455. Telephone: (612) 624-5059; fax: (612) 626-9871; email: linxx004@tc.umn.edu

\section{INTRODUCTION}

Mucoid otitis media (MOM) has been recently defined as chronic otitis media with mucoid effusion (Gates et al. 2002). It is one of the most common otological diseases that endangers hearing in humans and the leading cause for hearing loss in children. Unlike acute otitis media, MOM persists for a long period of time and causes conductive hearing loss. MOM is characterized by accumulation of mucous effusion in the middle ear cavity that reflects high concentrations of mucins. Identities of mucins in MOM are poorly understood at the present time and the underlying mechanism for production of mucins in MOM is basically unknown.

Mucins are integral structural components of the mucociliary transport system in the middle ear eustachian tube. Under normal conditions, mucin production in the normal middle ear is limited to the orifice of the eustachian tube and adjacent areas. A recent study demonstrated that middle ear epithelial cells have the potential to produce MUC5B mucins. Limited $M U C 5 B$ mucin mRNA transcripts have been detected in the promontory area, but no mucin glycoprotein has been found in the normal middle ear mucosa (Lin et al. 2001). Under inflammatory conditions, the middle ear responded with the expression of Muc1, Muc2, Muc3, Muc4, and Muc5 genes in rats (Lin et al. 2000; Tsuboi et al. 2002) and MUC5AC, MUC5B, MUC4, and MUC1 mucins in humans (Hutton et al. 1998; Kawano et al. 2000; Lin et al. 2001). How the middle ear mucin gene expression is altered in MOM is not clear, although few cases of 
MOM are included in our previous studies (Kawano et al. 2000; Lin et al. 2001).

We hypothesized that mucins in MOM were among the mucins known to the various tissues of the body, especially those expressed in the airways. Possible candidates include MUC4, MUC5AC, MUC5B, and MUC6-8 (Gendler and Spicer 1995; Kim and Gum 1995; Rose and Gendler 1997; Shankar et al. 1997). Therefore, various mucin cDNA probes and antibodies were used for the characterization and identification of mucins in MOM. The persistent accumulation of mucus in the middle ear cavity is likely to involve extensive proliferation of mucous cells and other mucin-producing cells in the middle ear mucosa. We thus used carbohydrate staining and mucin antibodies for identification of the cells contributing to mucus hyperproduction. To study the driving force for the production of mucins in the middle ear with MOM, we focused on the infiltrated inflammatory cells in the middle ear mucosa.

Identifying the mucins expressed in the middle ear with MOM and the factors that modulate mucin expression is an important step to understanding the pathogenesis of MOM. Understanding the pathogenesis of MOM would open a door for innovative therapeutic strategies for MOM.

\section{MATERIALS AND METHODS}

\section{Procurement of middle ear tissues and effusions}

The study protocol for collection and use of human specimens was reviewed and approved by the Institutional Review Board (IRB) of the University of Minnesota. Thirty middle ear biopsies were obtained from patients who underwent middle or inner ear surgery. Of these patients, 14 were diagnosed with MOM (inflamed middle ear) and had undergone middle ear surgery, 14 were diagnosed with noninflamed diseases such as otosclerosis and sensorineural hearing loss. A total $3 \mathrm{~mL}$ of middle ear effusion was collected from the above patients with MOM. Criteria for defining mucoid effusion in this study are the same as described previously, namely, presence of mucus strands in both gross examination and smear (Kawano et al. 2000). Eight immediate middle ear autopsies (3-6 h after death) were obtained from the patients who died from liver cancer, pneumonia, coronary artery disease, and infarcted bowel. None of the patients autopsied had a history of middle ear disease. Both biopsy and autopsy specimens were taken from the promontory area of the middle ear and used for isolation of total RNA or preparation of tissue section (see Table 1 in details). Inflamed middle ear specimens were compared with noninflamed middle ear specimens for evaluation of mucin

\section{TABLE 1}

Summary of both middle ear biopsy and autopsy specimens

Noninflamed

\begin{tabular}{|c|c|c|c|c|}
\hline \multirow[b]{3}{*}{$\begin{array}{c}\text { Use of } \\
\text { specimens }\end{array}$} & \multirow{3}{*}{$\begin{array}{c}\text { Inflamed } \\
\text { Biopsy } \\
\text { MOM }\end{array}$} & \multirow{2}{*}{\multicolumn{2}{|c|}{ Biopsy }} & \multirow{3}{*}{$\begin{array}{l}\text { Autopsy } \\
\text { Systemic } \\
\text { diseases }\end{array}$} \\
\hline & & & & \\
\hline & & Otosclerosis & $S N H L^{a}$ & \\
\hline Tissue sections & 4 & 3 & 4 & 3 \\
\hline RNA isolation & 10 & 3 & 4 & 5 \\
\hline Total & 14 & 6 & 8 & 8 \\
\hline
\end{tabular}

${ }^{a} \mathrm{SNHL}$ : sensorineural hearing loss.

${ }^{b}$ Liver cancer, pneumonia, coronary artery disease, infarcted bowel.

gene expression, mucous cell metaplasia/hyperplasia, and inflammatory cell infiltration/classification.

\section{Mucin mRNA analyses by in situ hybridization and Northern blot}

To characterize the mucin gene expression in the middle ears with MOM, in situ hybridization and Northern blot were performed as previously described (Lin et al. 1998, 2001). Mucin probes for this study included pum $24 \mathrm{p}$ for MUC1 tandem repeat (TR), SMUC41 for MUC2 TR, SIB 139 for MUC3 TR, M4oligo-1 for MUC4 TR, M4oligo-2 for MUC4 nontandem repeat (NTR), 4F for MUC5AC TR, hGBM4-1 for MUC5B TR, M5B for MUC5B NTR, 3F for MUC6 TR, M7oligo for MUC7 TR, and M8oligo for MUC8 TR. They were gifts from Drs. Carol B. Basbaum, Samuel B. Ho, James R. Gum Jr., and Dallas M. Swallow.

For in situ hybridization, middle ear tissue paraffin sections were prepared, deparaffinized routinely, and incubated with $5 \mu \mathrm{g} / \mathrm{mL}$ proteinase $\mathrm{K}$ for digestion of proteins on the surface of sections. The sections were then hybridized with $10^{5} \mathrm{cpm} / \mu \mathrm{L}$ of ${ }^{35} \mathrm{~S}$ sense (control) and antisense riboprobes for MUC1-4, MUC5AC, MUC5B, MUC6-8, respectively. The sections were washed under stringent conditions $(2 \times \mathrm{SSC}, 50 \%$ formamide, and $10 \mathrm{mM} \mathrm{DTT}$ at $60^{\circ} \mathrm{C}$ for $20 \mathrm{~min}$ ) and were digested with ribonuclease A $(25 \mu \mathrm{g} / \mathrm{mL})$ for elimination of nonspecific hybridization of riboprobes. After radioautographic exposures of 7 days at $4^{\circ} \mathrm{C}$, sections were developed and counterstained with hematoxylin. Expression of mucin genes in specimens was rated as " 0 " for no hybridizing signals, " 1 ", for $1-25 \%$, " 2 ", for $24-50 \%$, " 3 " for $51-75 \%$, or " 4 ", for $76-100 \%$ coverage of the epithelial layer. In situ hybridization data were viewed by two people and their grades were evaluated by the Kendall's rank correlation coefficient with +1 (complete concordance), -1 (complete disagreement), and values near zero indicating independence. Ten noninflamed 
middle ear specimens (3, 4, and 3 specimens, respectively, from otosclerosis, SNHL and systemic disease patients) served as controls.

For Northern analysis, 5-20 $\mu \mathrm{g}$ of the total RNA was denatured, size separated by electrophoresis on a $1.0 \%$ agarose gel, transferred onto a nylon membrane, and hybridized with $2 \times 10^{6}{ }^{32}$ P-radiolabeled cDNA probes for MUC1. The blot was first washed under stringent conditions and then exposed on a Kodak XAR film. The blot was then stripped with $0.1 \%$ sodium dodecyl sulfate (SDS) and reprobed with MUC2-4, MUC5AC, MUC5B, MUC6-8, $\beta$-actin cDNA probes. To confirm that Northern analysis with tandem repeat cDNA probes was quantitative, $M U C 5 B$ and MUC4 nontandem repeat cDNA probes were also used. Twelve noninflamed middle ear specimens (3, 4, 5 specimens, respectively, from otosclerosis, SNHL and systemic diseases) served as controls.

Mucin protein analysis by immunohistochemistry, ELISA, and electron microscopy

To study the expression of mucins in the middle ear tissues with MOM, immunohistochemistry was performed as previously described (Ho et al. 1995). Mucin antibodies for this study included 139H2 for MUC1 core protein (mouse MAb), MRP for MUC2 tandem repeat peptide (TRP, rabbit PAb), M3P for MUC3 TRP (rabbit PAb), M4P for MUC4 TRP (chicken PAb), M4-1 for MUC4 nontandem repeat peptide (chicken PAb), M5P for MUC5AC TRP (chicken PAb), M5BP for MUC5B TRP (chicken $\mathrm{PAb}$ ), and M6P for MUC6 TRP (chicken PAb). They were gifts from Drs. Young S. Kim, James R. Gum Jr., and John Hillkens. To study the identity of mucins in middle ear effusions, purification of middle ear mucin was performed as previously described (Lin et al. 1999). ELISA was performed on the mucins purified from the middle ear effusions as previously described (Lin et al. 2001). To study the image of middle ear mucins, electron microscopy was performed as previously described (Lin et al. 2001) on the purified middle ear mucins. Ten noninflamed middle ear specimens used in the above in situ hybridization served as controls.

\section{Goblet cell and inflammatory cell analyses}

To study the metaplasia/hyperplasia of goblet cells and infiltration of inflammatory cells in the middle ears with MOM, Alcian blue-periodic acid Schiffs (ABPAS) and hemotoxylin \& eosin (H\&E) were used. To study subpopulations of inflammatory cells, immunohistochemistry was performed. Ten noninflamed middle ear specimens used in the above in situ hybridization served as controls.
Goblet cell identification by AB-PAS stain. AB-PAS staining was performed routinely for evaluation of goblet cell metaplasia/hyperplasia. Goblet cells were identified using the method previously described (Kawano et al. 2000, 2002). Epithelial cells that stained violet or blue were identified as goblet cells and counted as previously described (Kawano et al. 2002). Goblet cells in the middle ears with MOM were compared with those in control middle ears and evaluated by the Student $t$-test. $P$ value $<0.05$ was considered statistically significant.

Inflammatory cell identification by H\&E. H\&E staining was performed routinely for evaluation of infiltration of inflammatory cells. Four areas, each 50 $\mu^{2}$, were randomly chosen from the submucosal layer, and inflammatory cells (leukocytes) within each area were counted under light microscopy as previously described (Kawano et al. 2000). The number of inflammatory cells in the middle ears with MOM was compared with those in the controls and evaluated by the Student $t$-test. $P$ value $<0.05$ was considered statistically significant.

Identification of subpopulations of inflammatory cells by cellular markers. Immunohistochemistry was performed as described above. Middle ear tissue sections were incubated with antibodies specifically against CD4, CD8, CD20, and CD68 antigens. CD4 monoclonal antibody (MAB379) was purchased from R \& D Systems Inc. (Minneapolis, MN) for $\mathrm{T}$ helper/inducer cells; CD8 (NCL-CD8-4B11), CD20 (NCLCD20-L26), and CD68 (NCL-CD68-KP1) antibodies were purchased from Novacastra (Britain) for cytotoxic/suppression $\mathrm{T}$ cells, $\mathrm{B}$ cells, and monocyte macrophages.

To study whether the expression of mucin mRNA transcripts, proliferation of goblet cells, and infiltration of inflammatory cells were related events, we evaluated the correlation among these events using the Student $t$-test. $P$ value $<0.05$ was considered statistically significant.

\section{RESULTS}

Expression of mucin mRNA in the middle ears with MOM

The biopsy middle ear specimens with MOM expressed both $M U C 5 B$ and MUC4 mucin genes. Abundant $M U C 5 B$ mucin mRNA transcripts were found in the thickened middle ear epithelium with MOM, whereas spotty MUC5B mucin mRNA transcripts were found in the control middle ears. The MUC4 mucin mRNA transcripts were found in the middle ears with MOM but not in the control ears (Fig. 1). Intensity data of $M U C 5 B$ and MUC4 mRNA transcripts were consistent between the two viewers: 

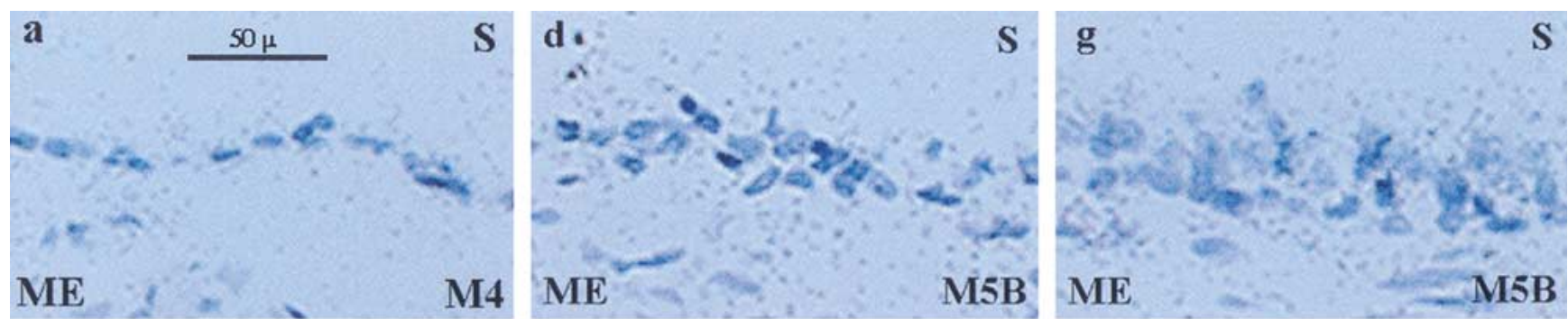

b

AS

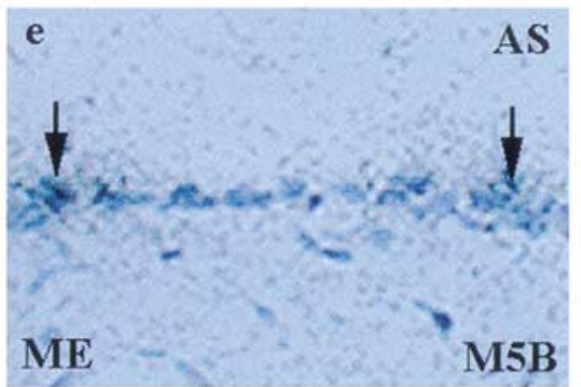

h

AS
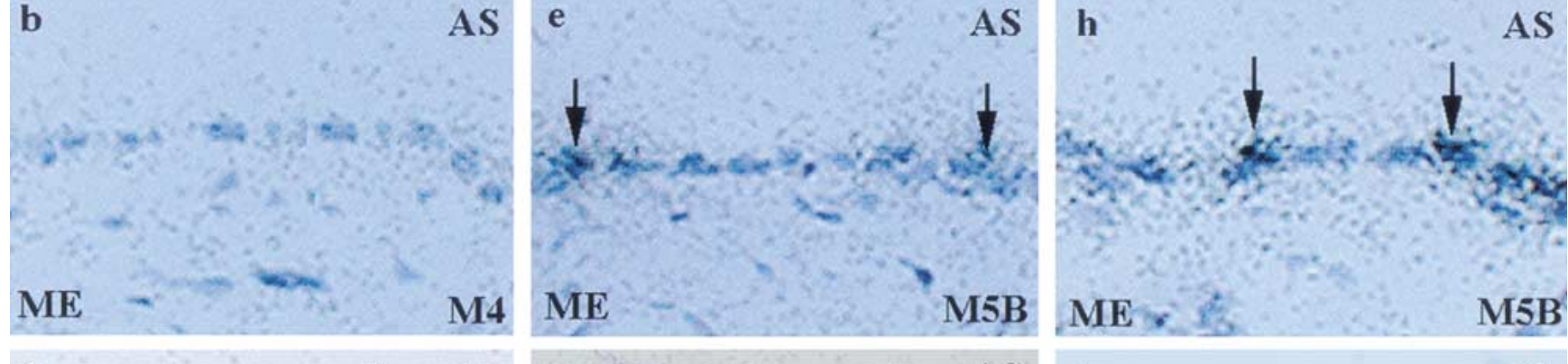

c

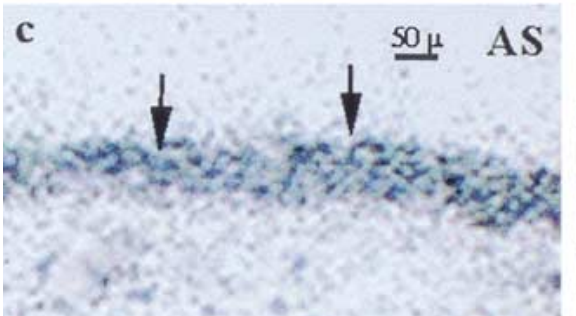

MOM

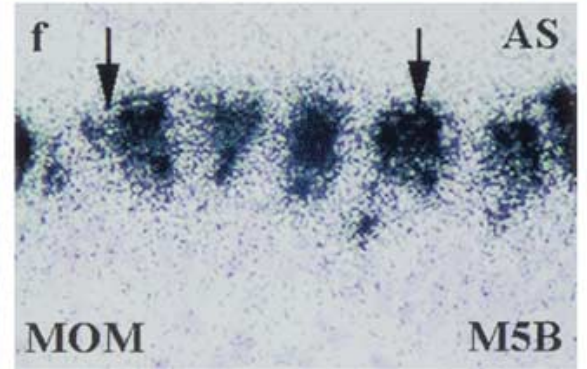

i

AS
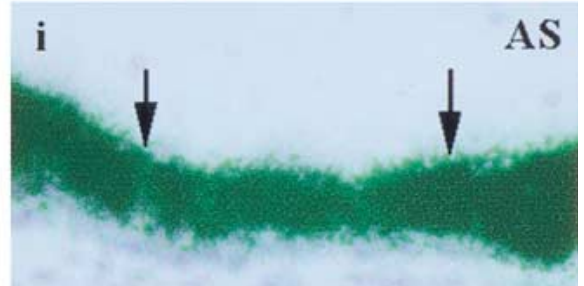

${ }^{5} \mathrm{M} 4$

M5B

MOM

M5B

FIG. 1. In situ MUC4 and MUC5B mucin mRNA transcripts in control middle ears (ME) and chronic otitis media with mucoid effusion (MOM). Upper row stands for sense riboprobe, no hybridizing signals; middle row and lower row stand for antisense riboprobe; black arrows indicate specific hybridizing signal of MUC4 and MUC5B mucin mRNA transcripts. Control middle ears (ME, middle row) expressed very limited $M U C 5 B$ mRNA transcripts (e and $\mathbf{h}$ ) but no MUC4 mRNA transcripts (b), whereas middle ears with MOM expressed abundant MUC5B (f and i) and MUC4 (c) mucin mRNA transcripts. (b) M4 = grade " 0 "; (c) M4 = grade "2" (e and h) M5B = grade "1"; (f) grade "3"; (i) grade "4". Original magnification: $400 \times$.

\section{TABLE 2}

The difference of mucin gene expression, goblet cells, and inflammatory cells between controls and MOM

\begin{tabular}{lccc}
\hline & Ctrl & MOM & $P$ value \\
\hline MUC5B & $0.8 \pm 0.32$ & $3 \pm 0.5$ & 0.00435 \\
MUC4 & 0 & $1.75 \pm 0.375$ & 0.00299 \\
GC & $7.4 \pm 2.08$ & $30.25 \pm 6.75$ & 0.00976 \\
WBC & 0 & $82.25 \pm 28.25$ & 0.00758 \\
\hline
\end{tabular}

the rank correlation coefficient (Kendall's tau) was 0.812 . It was obvious that the MUC4 mucin gene was activated or upregulated in MOM. Compared to the expression of the $M U C 5 B$ mucin gene, the expression of the MUC4 mucin gene was considered not strong. No other mucin gene expression, except for $M U C 5 B$ and MUC4, was detected in the middle ears with MOM by in situ hybridization. The data regarding intensity of $M U C 5 B$ and MUC4 mucin mRNA transcripts is presented in Table 2. The correlation of MUC5B and MUC4 with goblet cells and infiltrated inflammatory cells is presented in Table 3 .

\section{TABLE 3}

The correlation among the expression of mucin genes, infiltration of inflammatory cells, and proliferation of goblet cells

\begin{tabular}{lllr}
\hline$P$ value & MUC5B & MUC4 & WBC \\
\hline GC & 0.00182 & 0.00152 & 0.0278 \\
WBC & 0.00286 & 0.00278 & \\
MUC4 & 0.1339 & & \\
\hline
\end{tabular}

Northern blot analysis demonstrated $M U C 5 B$ and MUC4 mRNA expression from middle ear specimens with MOM, whereas only MUC5B mRNA was detected in the control ear specimens. No other mucin mRNA expression was detected in the middle ear specimens with MOM by Northern analysis. Positive controls for all $M U C$ s were positive and negative controls for all MUCs negative. Semiquantitative analysis of Northern blot data using the OptiQuant software (version 3.00, $\triangle$ Packard, Boston, MA) showed MUC5B and MUC4 mucin gene expression to be approximately 5 -fold and 6-fold higher in MOM specimens than in the 

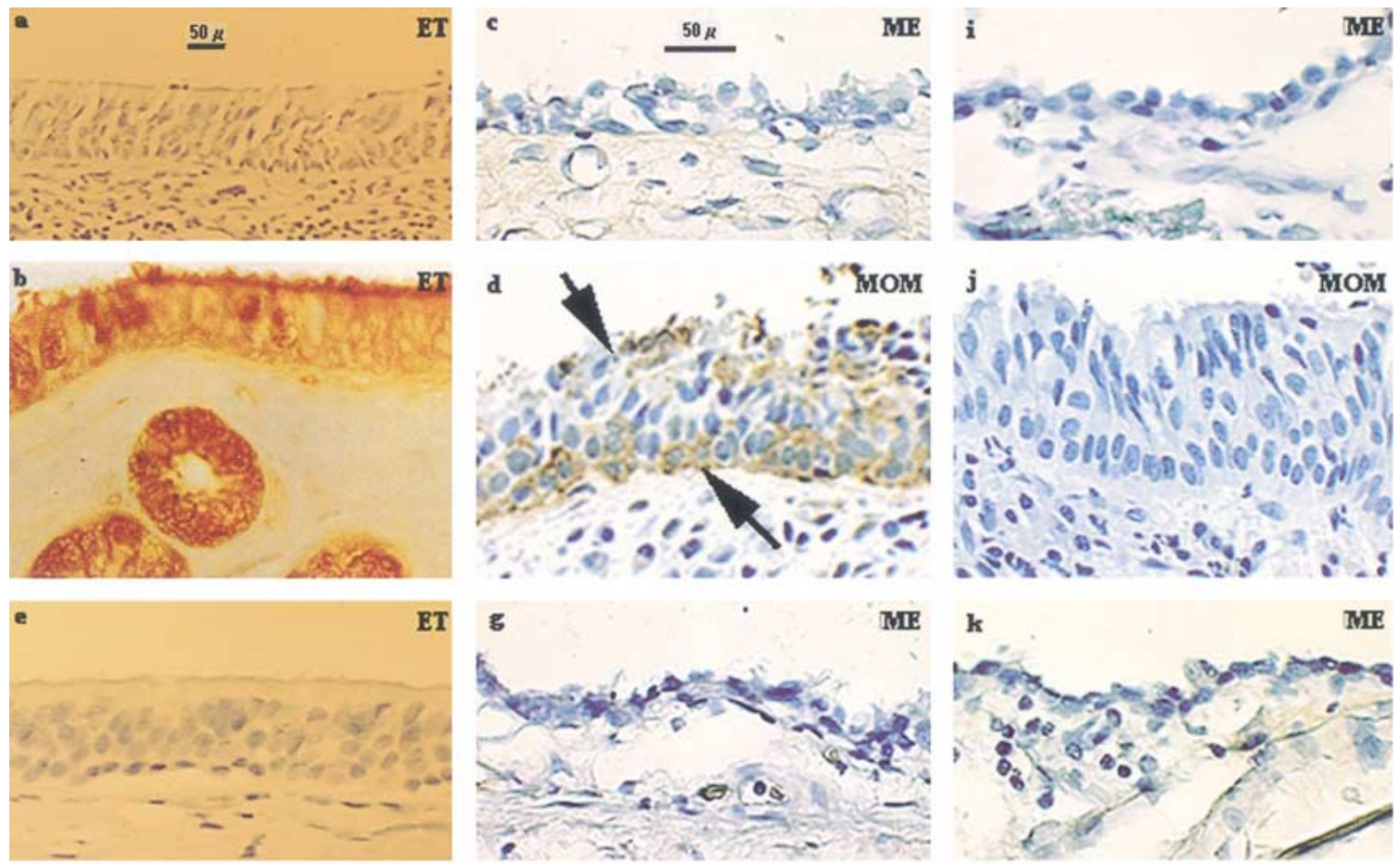

$\mathbf{k}$

ME
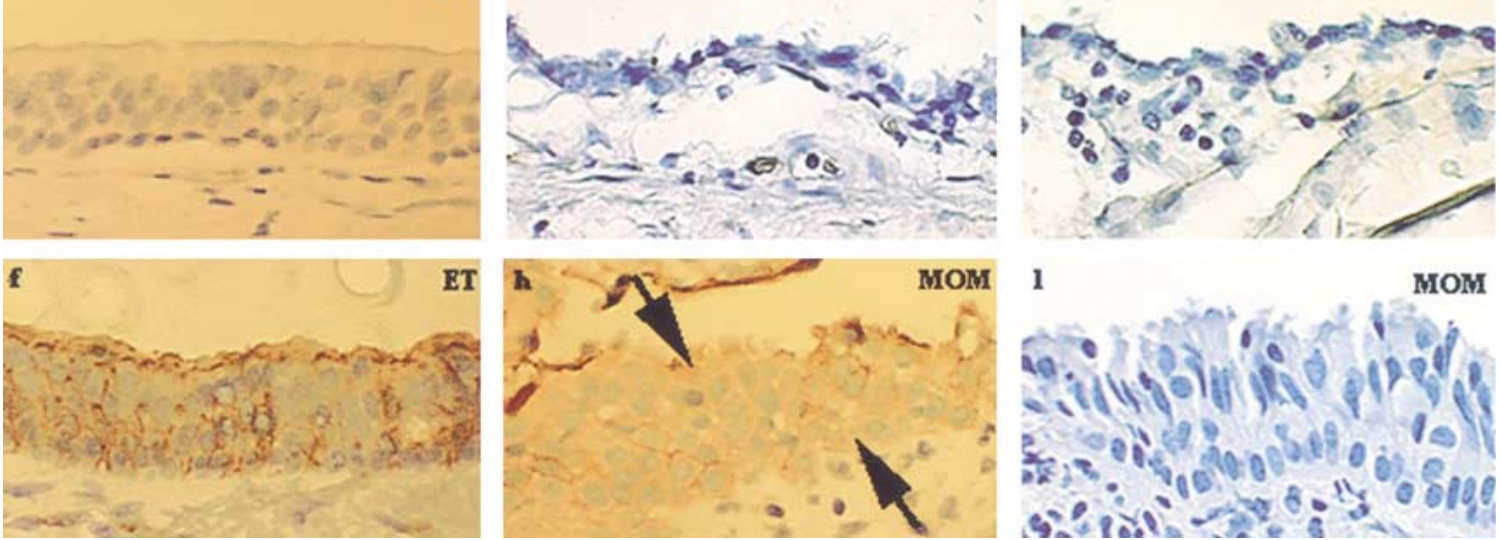

FIG. 2. Mucin glycoprotein expression in the middle ear with MOM. Middle ear epithelia with MOM reacted positively with MUC5B (arrows, d) and MUC4 (arrows, h) polyclonal antibodies, whereas noninflamed middle ear epithelia did not react with MUC5B (c) or MUC4 (g) polyclonal antibodies. Note that MUC5B and MUC4 mucin-producing cells spanned the entire middle ear epithelium MOM (arrows, $\mathbf{d}$ and $\mathbf{h}$ ) compared to noninflamed middle ears (c and
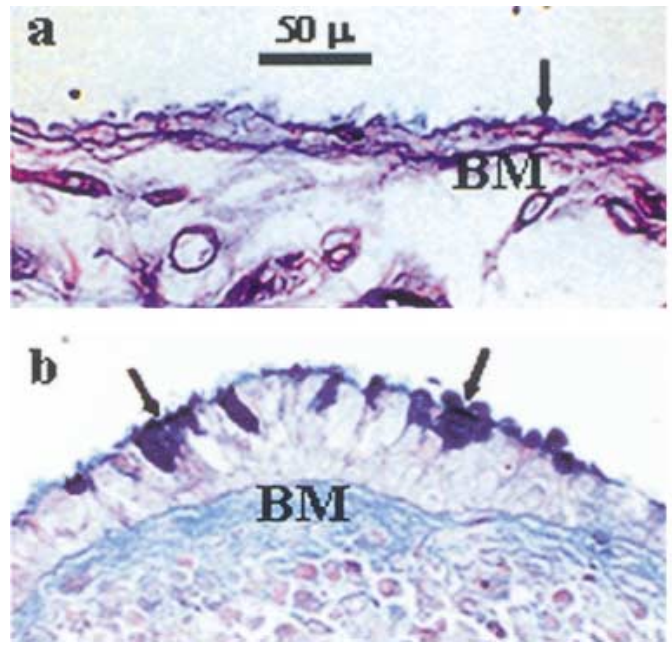

FIG. 3. Mucous cell metaplasia/hyperplasia in the middle ear with MOM. Middle ear specimen sections were fixed in formalin, embedded in paraffin, cut, and stained with AB-PAS and HE. Middle ears with MOM demonstrated abundant macroglycoconjugates (ABPAS) in the middle ear epithelial cells (b, arrows) as compared to the g). The middle ear tissues stained negatively to MUC5B and MUC4 preimmune sera as expected (third column and $\mathbf{a}$ and $\mathbf{e}$ ). The positive control eustachian tube (ET) tissues stained positively to MUC5B (b) and MUC4 (f) polyclonal antibodies but negatively to MUC5B preimmune (a) and MUC4 preimmune (e) sera. ME: noninflamed middle ear. Original magnification: $400 \times$ for the middle and right columns, $200 \times$ for the left column (eustachian tube).
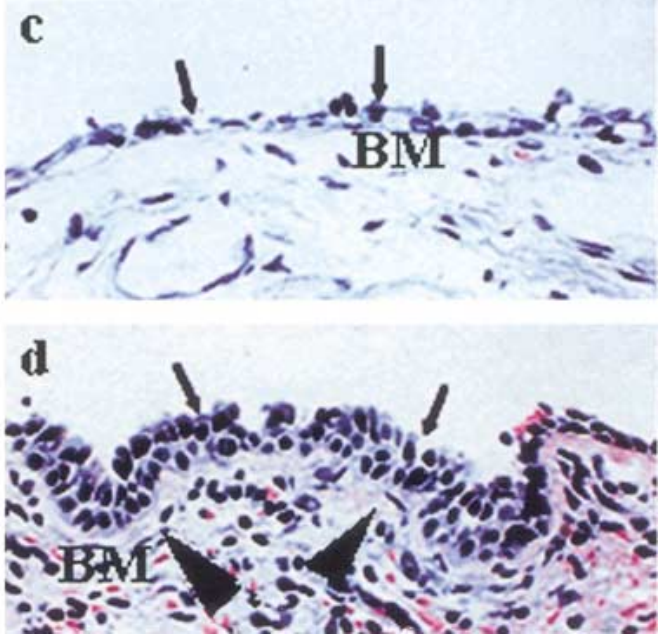

control middle ear mucosa (a, arrow). HE demonstrated a thickened and ciliated pseudostratified secretory epithelium (d, arrows) with inflammatory cell infiltration in the submucosal layer compared to the noninflamed middle ear mucosa (c, arrows). BM: basement membrane (arrowheads). Original magnification: 400x. 
control specimens, after normalization of expression by the housekeeping gene $\beta$-actin. The mucin mRNA expression data of MOM by Northern blot is highly similar to that of chronic otitis media (COM) [see Fig. 4 in Lin et al. (2001)]. It suggests that MOM is part of COM. Amount of mucin mRNA transcripts may vary between MOM and COM but the species of mRNA transcripts in MOM are similar to those in COM.

Expression of mucin glycoproteins in the middle ears with MOM in humans

Preimmune sera showed negative stain (Fig. 2, third column and panels a and e, data not shown for MUC1, MUC2, MUC3, MUC5AC, and MUC6). MUC5B mucin polyclonal antibody did not show any stain (Fig. 2c) with the noninflamed middle ear specimens. Note that the $M U C 5 B$ mRNA was found in the control specimens (Fig. 2), suggesting that normal middle ear epithelial cells are only potential MUC5B-producing cells. Expression of MUC5B and MUC4 antigens was obvious in middle ears with MOM (Fig. 2d and h, MOM) compared to noninflamed middle ears (Fig. 2c and $\mathrm{g}, \mathrm{ME})$. No other mucin proteins, including MUC1, MUC2, MUC3, MUC5AC, and MUC6, were detected by immunohistochemistry (data not shown). Positive control tissue eustachian tube demonstrated positive MUC5B and MUC4 antigens (Fig. 2b and $\mathrm{f}$ for MUC5B and MUC4, respectively).

Immunohistochemistry demonstrated extensive and widespread expression of MUC5B mucin in specimens with MOM (Fig. 2h, MOM), whereas none was noted in noninflamed middle ears (Fig. 2g, ME). Compared to the controls, an obvious increase of MUC5B and MUC4 mucins was observed in the middle ears with MOM.

\section{Epithelial thickening and mucous cell proliferation in human MOM}

Histology of the 4 middle ear mucosa taken from the promontory area of patients with MOM revealed pseudostratified epithelium. Epithelial thickening in the mucosa with MOM (Fig. 3d) was obvious compared to the control (Fig. 3c). The pseudostratified epithelium was considered to be highly secretory due to its abundant macroglycoconjugates (Fig. 3b). These specimens revealed abundant inflammatory cells (leukocytes) in the submucosa $(82.25 \pm 28.25 \times$ $10^{4}$ cells $/ \mu \mathrm{m}^{2}$ ) compared to those in the controls (none). The level of difference between controls and MOM is statistically significant $(P<0.01$, Table 2$)$. The infiltrated cells were mainly $\mathrm{T}$ cells (CD4, $17.53 \pm 3.30 \%$, and $\mathrm{CD} 8,34.24 \pm 3.43 \%, n=4)$, B cells (CD20, $38.97 \pm 0.45 \%, n=4)$, and monocyte macrophages (CD68, $9.26 \pm 1.68 \%, n=4)$. A typical pseudostratified epithelium is presented in Figure $3 \mathrm{~d}$ (H\&E stain). AB-PAS staining of pseudostratified epithelium revealed abundant macroglycoconjugates (Fig. 3b). The macroglycoconjugate-producing cells (goblet cells) were located mainly in the surface of the epithelium. The goblet cells in the middle ear mucosa with MOM were $30.25 \pm 6.75$ cells per high power field (HPF), whereas the goblet cells in the controls were $7.4 \pm 2.08$ cells/HPF. The level of difference between controls and MOM is statistically significant $(P<0.01)$. It was noted that goblet cells overlapped with MUC5B and/or MUC4 mucin-producing cells but did not necessarily represent all MUC5B and/or MUC4 positive cells in the middle ears with MOM. The difference of mucin gene expression, infiltration of inflammatory cells, and proliferation of goblet cells between intragroups is summarized in Table 2 .

Correlation among the expression of mucin genes, infiltration of inflammatory cells, and proliferation of goblet cells in human middle ear mucosa with MOM

The expression of the MUC5B and MUC4 mucin mRNA transcripts varied from case to case but tended to agree with infiltration of leukocytes in the submucosa. The level of correlation between expression of MUC5B or MUC4 mucin mRNA transcripts and infiltration of inflammatory cells is statistically significant $(P<0.01)$.

The expression of the MUC5B or MUC4 mucin mRNA transcripts was related to proliferation of goblet cells. The level of correlation between expression of $M U C 5 B$ or MUC4 mucin mRNA transcripts and proliferation of goblet cells is statistically significant $(P<0.01)$.

The infiltration of inflammatory cells in the submucosa is related to the proliferation of goblet cells in the epithelium. The level of correlation between infiltration of inflammatory cells and proliferation of goblet cells is statistically significant $(P<0.05)$.

The difference of mucin gene expression, infiltration of inflammatory cells, and proliferation of goblet cells between intergroups is summarized in Table 3 .

Identity and image of the middle ear mucins in human MOM

Mucins purified from MOM were recognized predominantly by the MUC5B mucin antibody but less recognized by the MUC4 mucin antibody. It is obvious that fraction 10 was rich in MUC5B in contrast to fraction 7 . Therefore, mucin in fraction 10 was submitted to further examination by electron micro- 
scopy. The middle ear mucins in fraction $10 \mathrm{dem}-$ onstrated a branched treelike polymer containing linear portions with thickened bulblike portions between linear portions or at the ends of linear portions. Again, the image of the middle ear mucins in MOM is highly similar to that of COM, as previously published [Fig. 6, in Lin et al. (2001)], except for highly branched structure of MOM mucin polymers.

\section{DISCUSSION}

The identities of mucins in MOM are MUC5B and MUC4 mucin glycoproteins which are highly similar to these in COM (Lin et al. 2001). Mucus polymers (treelike structure) remained after treatment with dithiothretol at $100 \mathrm{mM}$ for $24 \mathrm{~h}$. The mixture of the MUC5B and MUC4 mucins in MOM is extremely viscous since they possess a high density (1.4 mg/ $\mathrm{mL}$ ), a heavy carbohydrate coat (hexose-to-protein, $3: 1$ ), and a highly crosslinked (treelike) structure. Mucus accumulation in MOM is attributed to the hyperproduction of the MUC5B and MUC4 mucins since both MUC5B and MUC4 mucin mRNA and protein levels are highly upregulated in the middle ear epithelium. The data in the current study also indicated that the MUC5B mucin is the major soluble one in the middle ear mucosa and effusion, whereas MUC5AC mucin, which has been reported to be present in the middle ear effusion (Chung et al. 2002; Hutton et al. 1998), thick or thin, was not detectable in this study and in our previous studies (Kawano et al. 2000; Lin et al. 2001) by Northern blot and/or in situ hybridization. However, using RT-PCR, we were able to detect the MUC5AC and MUC1 mucin mRNA transcripts in the middle ear with MOM (data not shown). It suggests that the MUC5AC and MUC1 mucin genes be expressed in the middle ear with MOM at a very low level. Chung et al. (2002) demonstrated that a small number of goblet cells in the middle ear with MOM expressed the MUC5AC mucin. It is quite possible that the MUC5AC mucin antibodies used in the literature (Chung et al. 2002; Hutton et al. 1998) may in part cross-react with other mucins in middle ear effusion. It is generally accepted in the mucin community that some mucin antibodies have difficulties in distinguishing individual mucin members, and mucin cDNA/cRNA probes corresponding to their tandem repeat domains are much more specific in identification of individual mucins. In agreement with this study, both Hutton's and Chung's reports appreciated that MUC5AC mucin is a component of the middle ear mucins but not the major one (Chung et al. 2002; Hutton et al. 1998). It is obvious that there are some discrepancies regarding the MUC5AC mucin amount in middle ear.
However, there is no doubt that the MUC5AC mucin is not the major one in middle ear.

The MUC5B mucin gene, mapped to chromosome 11 p15 (Dufosse et al. 1993), contains a 10.7-kb large central exon that encodes various alternate subdomains (Desseyn et al. 1997), including imperfectly conserved repetitive tandem repeat units with sequences of 29 amino acids (SSTPGTAHTHTEQTTTATTPTATGTTATP) (Desseyn et al. 1997; Dufosse et al. 1993). MUC5B mucin tandem repeat units contain abundant $\mathrm{T}$ residues (14 out of 29 residues, potential sites for glycosylation) followed by $\mathrm{P}$ residues (potential recognition sites of glycosyltransferase). Up to $48 \%$ of amino acids within the tandem repeats of MUC5B mucin are potentially glycosylated.

At both ends of the molecule, MUC5B contains abundant cysteine residues (Keates et al. 1997) which are potential residues for formation of disulfide bonds inter- or intramolecularly and serve as a biochemical basis for dimerization or polymerization. Dimerization of mucin monomers is known to occur at the endoplasmic reticulum (Asker et al. 1998; Dekker and Strous 1990); however, it is not clear where dimerized mucins polymerize. It could occur at the packing stage of mucins within the mucus granules or after release onto the apical surface. Compared to COM mucins (Lin et al. 2001), human MOM mucins (a branched treelike strand) are highly polymerized through bulblike structures. The "bulbs" may represent nontandem repeat regions that are less glycosylated and rich in cysteine residues, likely the areas in which disulfide bonds could link inter- and intramolecularly between mucin monomers. The linear portion of the strand between bulbs may represent the tandem repeat region of mucin, which is heavily glycosylated and, therefore, rigid. With such a large tandem repeat central area, one would expect that MUC5B mucin acts to trap or pack pathogens and their cell wall components which contain abundant carbohydrates (lectin ligands for mucin carbohydrate receptors). It has been shown that mucins, isolated from middle ear effusion, bind to bacterial outer membrane proteins (Reddy et al. 1997). In the literature, bacterial cell wall components have been reported in the middle ear effusion (Leinonen 1980; Ovesen and Ledet 1992). Existence of viscous mucins (MUC5B) with trapped bacterial cell wall components in the middle ear cavity may account for infiltration of chronic inflammatory cells in the middle ear cleft even though bacterial culture of mucus effusion is negative. It also explains that mucus effusion drainage through intuberlation is effective for treatment of MOM, whereas antibiotic treatment is not. In some cases, mucus effusions are free of bacterial cell wall components but infiltration of chronic inflammatory cells occurs. It suggests that mucus accumulation itself also matters. 
It has been shown in the current study that MUC4 adds to the mucin pool of MOM from ELISA data of middle ear fluid, a similar situation seen in COM (Lin et al. 2001). MUC4 is regarded as a membrane-bound mucin and is present in the entire middle ear epithelium, including ciliated, intermediate, and basal cells under diseased conditions (Fig. 1). It may participate in formation of mucous strands in MOM. The release of MUC4 from the membrane may occur in the presence of proteases (Kim et al. 1987) that truncate MUC4 right above transmembrane domain and leave the transmembrane domain and intracellular tail (COOH terminus) to the bilayer of membrane and release the rest of MUC4 into the middle ear cavity. It has been noted that the MUC4 mucin in breast tissue possesses a different version that lacks the transmembrane domain; therefore, it is meant to release directly into milk.

Excessive production of mucins in MOM is attributed to goblet cell metaplasia/hyperplasia in the middle ear cleft (Lim 1979; Tos and Bak-Pedersen 1976, 1977). Except for goblet cell metaplasia/ hyperplasia, we demonstrated in this study that both MUC5B and MUC4 mucin-producing cells in the middle ear epithelium are highly populated, not only in the surface but also in the entire epithelium layer. This led us to conclude that MUC5B and MUC4 cell metaplasia/hyperplasia is an essential problem of MOM in humans. Goblet cell metaplasia/hyperplasia (Fig. 2) is obvious in MOM but did not include all mucin-producing cells (Fig. 1d and h). It does not reflect those potential cells in the epithelium that are also recruited to express MUC5B and MUC4 mucins under the conditions of MOM. The similar phenomenon is also observed in COM where the MUC5B mucin probe labeled more cells than that of AB-PAS in serial sections (Kawano et al. 2000). Therefore, we propose to use MUC5B and MUC4 cell metaplasia/ hyperplasia for describing abnormal mucin production in MOM or COM, instead of goblet cell metaplasia/hyperplasia, which accounts for only part of the mucin-producing cells.

The mechanism for MUC5B and MUC4 cell metaplasia/hyperplasia is not currently understood but likely involves extensive infiltration of inflammatory cells in the middle ear cleft. As shown in this study, inflammatory cells were mainly $\mathrm{T}$ cells identified with CD4 and CD8 antibodies, B cells with CD20, and monocyte macrophages with CD68. TNF- $\alpha$, one of the inflammatory products from the above- mentioned inflammatory cells (CD68 positive cells), may serve as an inducer for expression of MUC5B and MUC4 mucin genes as well as MUC5B and MUC4 cell metaplasia/hyperplasia, since inoculation of TNF- $\alpha$ into rat middle ear induced mucin expression (Lin et al. 2000) and phenotypic thick effusion in the middle ear cavity and mucous cell metaplasia/hyperplasia in the middle ear mucosa (Kawano et al. 2002). Evidence accumulated to date suggests that mucin upregulation involves infectious factors such as bacteria and their products (Kim et al. 2001; Li et al. 1997, 1998, 1999; Wang et al. 2002) as well as host response factors, such as proinflammatory cytokines (Lin et al. 2000; Moon et al. 2000), nitric oxide (Li et al. 2000; Rose et al. 1996), retinoic acid, and hydrocortisone (Moon et al. 2000). The regulatory process involves multiple signal transduction pathways (Lin et al. 2002; Wang et al. 2002). Data obtained from cytokine knockout mice suggest that mucin regulation is not controlled by a single factor but perhaps by an extensive regulatory network, and to knockout a target gene may not significantly inhibit mucin production (Shekels et al. 2001). The data suggest that a cocktaillike therapeutic intervention may be required for reduction of mucin hyperproduction.

On the other hand, MUC4 itself may have a role in cellular proliferation of MOM. Unlike other mucins, MUC4 contains MUC4 $\alpha$ and MUC4 $\beta$ subunits. MUC4 $\beta$ possesses two epidermal growth factor (EGF)-like domains which contain all of the consensus residues found in EGF-like sequences of proteins known to possess growth factor activity (Sheng et al. 1992). It has been shown that MUC4 acts as a ligand and modulator for the receptor tyrosine kinase ErbB $_{2}$ (Carraway et al. 1999, 2000), suggestive of its role in cellular growth and proliferation. How MUC4 expression is upregulated and how that affects middle ear cellular proliferation is currently unknown. Study of the molecular mechanism of MUC5B and MUC4 cell metaplasia/hyperplasia will open a new window for a better understanding of the disease and for providing the rationale for innovative therapeutic strategies for MOM.

\section{ACKNOWLEDGMENTS}

We wish to thank Drs. Carol Basbaum, Young S. Kim, James R. Gum,Jr., John Hilkens, and Dallas M. Swallow for their kindly gifts of mucin cDNA probes and antibodies, and Leslie O'Bryan for her editing assistance in the preparation of this manuscript. This study was supported in part by NIH grant No. R01 DC03433 and P30 DC04660 from the National Institutes on Deafness and Other Communication Disorders, and the Lions 5M Multiple District Hearing Foundation.

\section{REFERENCES}

Asker N, Axelsson MA, Olofsson S-O, Hansson GC. Dimerization of the human MUC2 mucin in the endoplasmic reticulum is followed by a N-glycosylation-dependent transfer of the mono- 
and dimers to the Golgi apparatus. J. Biol. Chem. 273:1885718863, 1998.

Carraway KL 3rd, Rossi EA, Komatsu M, Price-Schiavi SA, Huang PM, Guy PM, Carvajal Me, Fregien N, Carraway CA, Carraway KL. An intramembrane modulator of the ErbB2 receptor tyrosine kinase that potentiates neuregulin signaling. J. Biol. Chem. 274:5263-5266, 1999.

Carraway KL, Price-Schiavi SA, Komatsu M, Idris N, Perez A, Li P, Jepson S, Zhu X, Carvajal ME, Carraway CA. Multiple facets of sialomucin complex/MUC4, a membrane mucin and erbb2 ligand, in tumors and tissues (Y2K update). Front. Biosci. 5:D95-D107, 2000.

Chung MH, Choi JY, Lee WS, Kim HN, Yoon JH. Compositional difference in middle ear effusion: mucous versus serous. Laryngoscope 112:152-155, 2002.

DekKer J, Strous GL. Covalent oligomerization of rat gastric mucin occurs in the rough endoplasmic reticulum, is N-glycosylationdependent, and precedes initial $O$-glycosylation. J. Biol. Chem. 265:18116-18122, 1990.

Desseyn JL, Guyonnet-Duperat V, Porchet N, Aubert JP, Laine A. Human mucin gene MUC5B, the 10.7-kb large central exon encodes various alternate subdomains resulting in a super-repeat. Structural evidence for a 11 p15.5 gene family. J. Biol. Chem. 272:3168-3178, 1997.

Dufosse J, Porchet N, Audie J-P, Guyonnet-Duperat V, Laine A, Van-Seuningen I, Marrakchi S, Degand P, Auert J-P. Degenerate 87-base-pair tandem repeats create hydrophilic/hydrophobic alternating domains in human mucin peptides mapped to 11p15. Biochem. J. 293:329-337, 1993.

Gates Ga, Klein JO, lim DJ, Mogi G, Ogra Pl, Pararella MM, PARAdise JL, Tos M. Recent advances in otitis media. 1. Definitions, terminology, and classification of otitis media. Ann. Otol. Rhinol. Laryngol. Suppl. 188:8-18, 2002.

Gendler SJ, SpICER AP. Epithelial mucin genes. Annu. Rev. Physiol. 57:607-634, 1995.

Ho SB, Shekels LL, Toribara NW, Kim YS, Lyftogt C, Cherwitz DL, NiEHans GA. Mucin gene expression in normal, preneoplastic, and neoplastic human gastric epithelium. Cancer Res. 55:26812690, 1995.

Hutton DA, Fogg FJ, Kubba H, Birchall JP, Pearson JP. Heterogeneity in the protein cores of mucins isolated from human middle ear effusions: evidence for expression of different mucin gene products. Glycoconjugate J. 15:283-291, 1998.

Kawano H, Haruta A, Tsuboi Y, Kim Y, Schachern PA, Paparella J, Lin J. Induction of mucous cell metaplasia by tumor necrosis factor alpha in rat middle ear: the pathologic basis for mucin hyperproduction in mucoid otitis media. Ann. Otol. Rhinol. Laryngol. 111:415-422, 2002.

Kawano H, Paparella MM, Ho SB, Schachern P, Morizono N, Le J, LIN J. Identification of MUC5B mucin gene in human middle ear with chronic otitis media. Laryngoscope 110:668$673,2000$.

Keates AC, Nunes DP, Afdhal NH, Troxler RF, Offner GD. Molecular cloning of a major human gall bladder mucin: complete C-terminal sequence and genomic organization of MUC5B. Biochem. J. 324:295-303, 1997.

KIм HY, AнN BY, Chо Y. Structural basis for the inactivation of retinoblastoma tumor suppressor by SV40 large T antigen. EMBO J. 20:295-304, 2001.

Kim KC, Wasano K, Niles RM, Schuster JE, Stone PJ, Brody JS. Human neutrophil elastase releases cell surface mucins from primary cultures of hamster tracheal epithelial cells. Proc. Natl. Acad. Sci. USA 84:9304-9308, 1987.

KIM YS, GUM JR JR. Diversity of mucin genes, structure, function, and expression. Gasteroenterology 109:999-1001, 1995.

LEINONEN MK. Detection of pneumococcal capsular polysaccharide antigens by latex agglutination, counterimmunoelectropho- resis, and radioimmunoassay in middle ear exudates in acute otitis media. J. Clin. Microbiol. 11:135-140, 1980.

Li JD, Dohrman AF, Gallup M, Miyata S, Gum JR, Kim YS, Nadel JA, Prince A, Basbaum CB. Transcriptional activation of mucin by Pseudomonas aeruginosa lipopolysaccharide in the pathogenesis of cystic fibrosis lung disease. Proc. Natl. Acad. Sci. USA 94:967972, 1997.

Li JD, Feng W, Gallup M, Kim JH, Gum J, Kim Y, Basbaum C. Activation of NF-kappaB via a Src-dependent Ras-MAPK-pp90rsk pathway is required for Pseudomonas aeruginosa-induced mucin overproduction in epithelial cells. Proc. Natl. Acad. Sci. USA 95:5718-5723, 1998.

Li W, Lin J, Adams GL, Juhn SK. Expression of inducible nitric oxide synthase (iNOS) in middle ear epithelial cells by IL-1beta and TNF-alpha. Int. J. Pediatr. Otorhinolaryngol. 55:91-98, 2000.

Lim DJ. Normal and pathological mucosa of the middle ear and Eustachian tube. Clin. Otolaryngol. 4:213-234, 1979.

Lin J, Haruta A, Kawano H, Ho SB, Adams GL, Juhn SK, Kim YK. Induction of mucin gene expression in middle ear of rats by tumor necrosis factor- $\alpha$ : potential cause for mucoid otitis media. J. Infect. Dis. 182:882-887, 2000.

Lin J, PAPARELla MM, Ho SB. RNA analysis on autopsy eustachian tube tissues: an addition to temporal bone histopathology. Acta Otolaryngol. 119:787-795, 1998.

Lin J, Tsuboi Y, Pan W, Giebink GS, Adams GL, Kim Y. Analysis by cDNA microarrays of altered gene expression in middle ears of rats following pneumococcal infection. Int. J. Pediatr. Otorhinolaryngol. 65:203-211, 2002.

Lin J, Tsuprun V, Kawano H, Paparella MM, Zhang Z, Anway RE, Ho SB. Characterization of mucins in human middle ear and Eustachian tube. Am. J. Physiol. 280:L1157-1167, 2001.

Lin J, Vambutas A, Haruta A, Paparella MM, Giebink GS, Kim Y. Pneumococcus activation of the 5-lipoxygenase pathway and production of glycoproteins in the middle ear of rats. J. Infect. Dis. 179:1145-1151, 1999.

Moon SK, Yoo JH, Kim HN, Lim DJ, Chung MH. Effects of retinoic acid, triiodothyronine and hydrocortisone on mucin and lysozyme expression in cultured human middle ear epithelial cells. Acta Otolaryngol. 120:944-949, 2000.

OvESEN T, LEDET T. Bacteria and endotoxin in middle ear fluid and the course of secretory otitis media. Clin. Otolaryngol. 17:531534, 1992.

Reddy MS, Murphy TF, Faden HS, Bernstein JM. Middle ear mucin glycoprotein: purification and interaction with nontypable Haemophilus influenzae and Moraxella catarrhalis. Otolaryngol. Head Neck Surg. 116:175-180, 1997.

Rose AS, Prazma J, Randell SH, Baggett HC, Pillsbury JC. Lipopolysaccharide increases release of mucin in a rat model of chronic otitis media with effusion. Assoc. Res. Otolaryngol. Abs. 37:, 1996.

Rose MC, Gendler SJ. Basic mechanisms and clinical perspectives. In: Gendler D, Rogers M (eds) Airway Mucus. Birkhauser Publishing Limited, Boston, pp 41-66, 1997.

Shankar V, Pichan P, Eddy Jr RL, Tonk V, Nowak N, Sait SN, Shows TB, Schultz RE, Gotway G, Elkins RC, Gilmore MS, SACHDEV GP. Chromosomal localization of a human mucin gene (MUC8) and cloning of the cDNA corresponding to the carboxy terminus. Am. J. Respir. Cell. Mol. Biol. 16:232-241, 1997.

Shekels LL, Anway Re, Lin J, Kennedy MW, Garside P, Lawrence SB, Ho SB. Coordinated Muc2 and Muc3 mucin gene expression in Trichinella spiralis infection in wild-type and cytokinedeficient mice. Dig. Dis. Sci. 46:1757-1764, 2001.

Sheng Z, Wu K, Carraway KL, Fregien N. Molecular cloning of the transmembrane component of the 13762 mammary adenocarcinoma sialomucin complex. A new member of the epidermal 
growth factor superfamily. J. Biol. Chem. 267:16341-16346, 1992.

Tos M, BaK-Pedersen K. Secretory otitis. Histopathology and goblet-cell density in the eustachian tube and middle ear in children. J. Laryngol. Otol. 90:475-485, 1976.

Tos M, BAK-PEDERSEN K. Goblet cell population in the pathological middle ear and eustachian tube of children and adults. Ann. Otol. Rhinol. Laryngol. 86:209-218, 1977.
Tsuboi Y, Kim Y, Paparella MM, Chen NQ, Schachern P, Lin J. Pattern changes of mucin gene expression with pneumococcal otitis media. Int. J. Pediatr. Otolaryngol. 61:23-30, 2002.

Wang B, Lim DJ, Han J, Kim YS, Basbaum CB, Li JD. Novel cytoplasmic proteins of nontypable Haemophilus influenzae up-regulate human MUC5AC mucin transcription via a positive p38 mitogen-activated protein kinase pathway and a negative phosphoinositide 3-kinase-Akt pathway. J. Biol. Chem. 277:949-957, 2002. 